\title{
Assessment of the flexibility of elite athletes using the modified Thomas test
}

\author{
D Harvey
}

\begin{abstract}
Aim-To analyse the modified Thomas test and obtain measures of flexibility for the iliopsoas, quadriceps and tensor fascia lata/iliotibial band.

Method-The modified Thomas test was used to determine the range of flexibility of 117 elite athletes in tennis, basketball, rowing, and running.

Results and conclusion-The study has provided objective data for a clinical test measuring flexibility of the iliopsoas, quadriceps, and tensor fascia latal iliotibial band. It is recommended that sufficient flexibility is obtained to perform a specific sport and that asymmetries between limbs are addressed.

(Br F Sports Med 1998;32:68-70)
\end{abstract}

Keywords: flexibility; iliopsoas; quadriceps; tensor fascia lata/iliotibial band; elite athletes

Sports injury prevention is the most desirable and cost effective way of reducing the risk of injury in sport. Not all injuries are "unavoidable accidents", therefore, with increased participation, injury prevention should be encouraged as a complementary process. Injury prevention firstly requires injury analysis to establish the magnitude, extent, and cause of the problem. ${ }^{1-3}$ Interventions designed to reduce the effect of the injury such as protective equipment or muscle strengthening can be introduced and then evaluated. ${ }^{4-6}$

Identification of risk factors for injury is critical for the effective prevention of injury. Risk factors are categorised into internal (personal) and external (environment). ${ }^{37}$ Environmental factors can be addressed with protective equipment and rule changes, but the internal factors are more difficult to address. ${ }^{28}$ Most injuries result from a multitude of factors, so it is very difficult to ascertain the direct influence of a factor such as flexibility, muscle strength, and athletic technique. ${ }^{1}$ To be able to measure the influence of these factors on the risk, incidence, and severity of injury, objective and specific tests need to be developed and validated. Musculoskeletal screening of athletes is an assessment designed to detect internal abnormalities that may increase the risk of injury for an individual. ${ }^{59}$

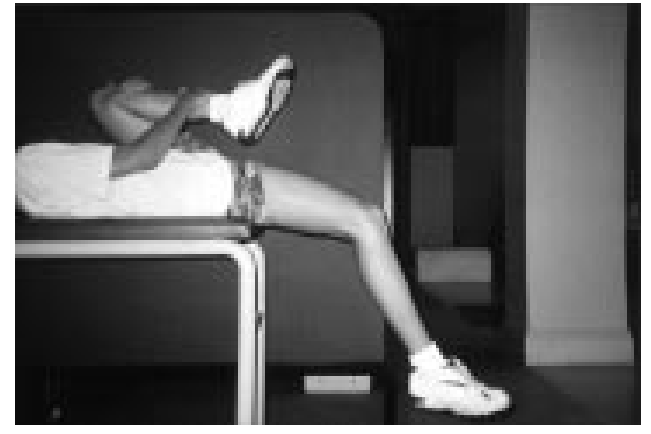

Figure 1 Modified Thomas test position.

\section{Aims and methods}

The purpose of this study was to analyse the modified Thomas test and obtain measures of flexibility for the iliopsoas, quadriceps, and tensor fascia lata/iliotibial band (TFL/ITB). ${ }^{10}$ Flexibility measures are one of the components of musculoskeletal screening. This study compared 117 elite athletes in tennis, basketball, rowing, and running to determine their range of flexibility. Comparisons between sports, gender, and limb dominance were also analysed.

For the modified Thomas test, the subject sat on the end of the plinth, rolled back on to the plinth, and held both knees to the chest. This ensured that the lumbar spine was flat on the plinth and the pelvis was in posterior rotation. The subject held the contralateral hip in maximal flexion with the arms, while the tested limb was lowered towards the floor (fig 1).

Three angles were measured for each limb and were repeated on alternate limbs to obtain data for two trials. Length of iliopsoas (test 1) was determined by measuring the angle of hip flexion (fig 2). Test 2 measured the passive length of the quadriceps by determining the knee flexion angle (fig 3). The hip abduction angle relative to the femur and angle of the pelvis represents the effect of TFL/ITB flexibility (fig 4).

\section{Results}

Raw data were collected for 117 subjects; the intraclass correlations for the two trials were extremely high (0.91 to 0.94$)$. As the frequency distributions of the results approximated to a normal curve, parametric statistics were considered appropriate. The dependent measures 


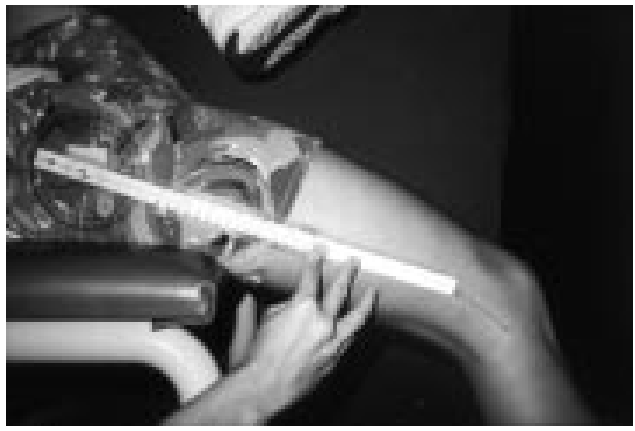

Figure 2 Measuring iliopsoas flexibility.

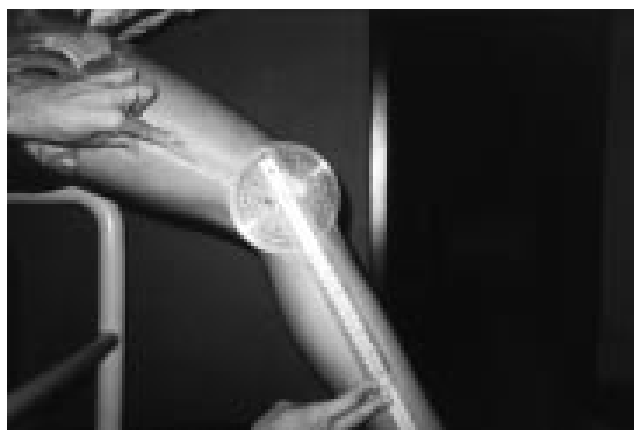

Figure 3 Measuring quadriceps flexibility.

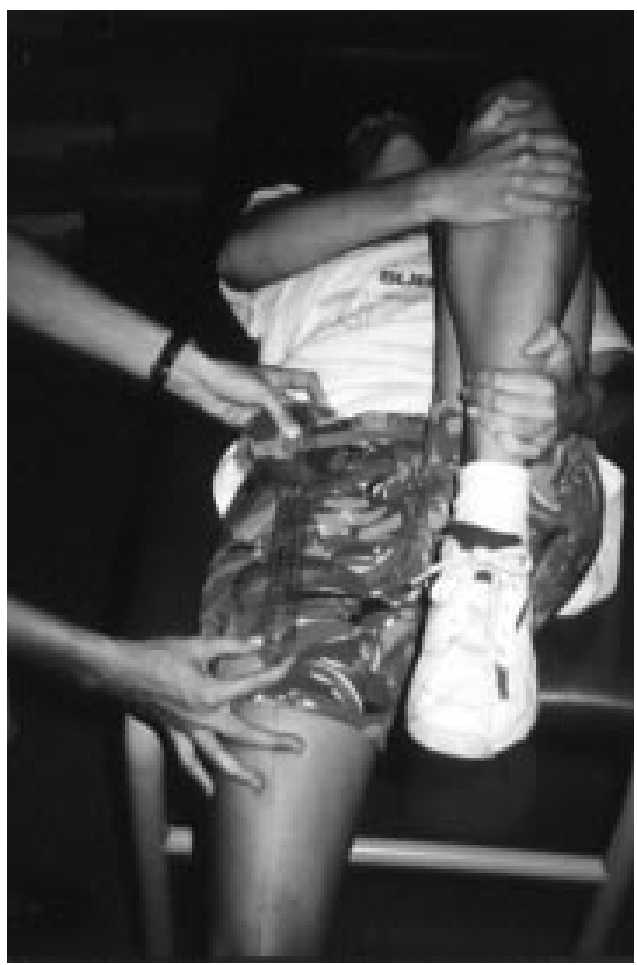

Figure 4 Measuring tensor fascia lata/iliotibial flexibility.

Table 1 Mean (SD) flexibility for iliopsoas, quadriceps, and tensor fascia lataliliotibial band (TFL/ITB) across sports

\begin{tabular}{llll}
\hline \multirow{2}{*}{ Sport } & \multicolumn{2}{l}{ foint angle ()} & \\
\cline { 2 - 4 } & Iliopsoas & Quadriceps & TFL/ITB \\
\hline Rowing & $-10.73(5.97)$ & $56.03(8.37)$ & $15.43(3.48)$ \\
Basketball & $-11.82(4.89)$ & $53.47(6.58)$ & $15.67(4.55)$ \\
Running & $-14.15(4.67)$ & $50.59(7.89)$ & $15.86(3.47)$ \\
Tennis & $-10.93(6.01)$ & $49.94(5.58)$ & $15.33(3.50)$ \\
Grand mean & $-11.91(5.57)$ & $52.51(7.56)$ & $15.57(3.96)$ \\
\hline
\end{tabular}

were submitted to separate four way analyses of variance with main effect for sport, sex, limb, and trial, with repeated measures on trial. Table 1 gives the results for test measures and grand means.

Flexibility of the iliopsoas was expressed as the angle of hip flexion, and the grand mean was $-11.9^{\circ}$. This meant that most athletes exhibited flexibility that allowed the leg to hang below horizontal. The analysis of variance showed that the non-dominant limb was more flexible than the dominant limb, and that the tennis players and rowers were less flexible than the runners.

The mean angle for test 2 , the quadriceps, was $52.5^{\circ}$. Significant differences were detected in flexibility, and a post hoc analysis using Neuman-Keuls showed that the runners and tennis players were less flexible than rowers and basketball players. Tightness of the TFL/ ITB was suggested to be evident as an increased angle of hip abduction (test 3 ). The mean for all subjects was $15.6^{\circ}$, and there were no significant differences between sport, gender, or limbs.

\section{Discussion}

An investigation of flexibility in elite athletes using the modified Thomas test was conducted in an attempt to provide some objective data for this clinical test. The results from this study question the accepted "normal" range proposed by Janda, ${ }^{10}$ which was that the femur should be horizontal, therefore $0^{\circ}$, the knee flexed to $90^{\circ}$, and the femur in neutral apparent abduction. Values from this study showed measures of about $-12^{\circ}$ from horizontal for the femur, $52^{\circ}$ for knee flexion, and $15^{\circ}$ of hip abduction relative to the pelvis.

Differences in results when comparing Janda's test and the modified Thomas test position could be related to several factors. If the contralateral hip is not held maximally flexed to the chest, this allows the opposite femur to drop because of the anterior rotation of the pelvis. In this position there is less tension on the iliopsoas and the quadriceps, so the angles of $0^{\circ}$ hip flexion and $90^{\circ}$ knee flexion are more easily achieved. For consistency, it is important that the athlete holds the contrateral limb maximally to the chest.

The angle of hip abduction in the modified Thomas test also differed from Janda's description. In Janda's test, normal hip abduction was assumed when the femur was aligned with the trunk. Owing to the difficulty of standardising the amount of trunk side flexion and pelvic rotation, there is significant potential for error using this subjective measure. The modified Thomas test measures the angle of femur abduction relative to the pelvis, which is an objective measure, and the pelvic position is consistent for test-retest comparisons.

Quadriceps flexibility differed between the sports analysed in this study, which gives support to the concept that flexibility should be considered on a sport specific basis. In this study, rowers exhibited greater quadriceps flexibility than runners and tennis players $(\mathrm{p}<0.05)$. Rowers are required to obtain 
maximal hip and knee flexion before the catch to maximise stroke length, thereby working functionally through a greater range of movement than tennis players and middle distance runners. Although not statistically significant, the rowers and tennis players had less iliopsoas flexibility than runners. Runners can obtain $10-20^{\circ}$ of hip extension in their natural stride, whereas rowers and tennis players are in a position of hip flexion for most of their activity. ${ }^{11}$

Poor flexibility is associated with soft tissue injuries, but it is still not clear from the research whether insufficient or excessive flexibility are conclusive predictors for injury. The coach or physiotherapist should consider the demands of the sport and ensure that the athlete has the flexibility to perform the required skills.

Differences between sexes and limb dominance were not conclusively established in this study. It is recommended that irrespective of gender, sufficient flexibility is obtained to perform the sport and that asymmetries between limbs are addressed. The major consequence of this study is that there are now objective data available for a clinical test measuring flexibility of the iliopsoas, quadriceps, and TFL/ITB. Further data collection from many sports science and sports medicine professionals will assist in establishing sport specific norms for use in musculoskeletal screening of athletes. Ultimately these data can be used to identify risk factors that can be influenced to reduce the incidence of sports injuries. The limitations of this study is the extrapolation of a joint angle to relate to flexibility of soft tissues. Further research is required to establish a relation between these measures.

1 Meeuwisse WH. Predictability of sports injuries. What is the epidemiological evidence? Sports Med 1991;12:8-15.

2 van Mechelen W, Hlobil H, Kemper HGG. Incidence, severity, aetiology and prevention of sports related injuries. Sports Med 1992;14:82-9.

3 Lysens RJ, de Weerdt W, Nieuwboer A. Factors associated with injury proneness. Sports Med 1991;12:281-9.

4 Knapik JJ, Jones BH, Bauman CL, Harris JM. Strength, flexibility and athletic injuries. Sports Med 1992;14:277-88.

5 Kibler WB. The sport pre-participation fitness examination. Kibler WB. The sport pre-participation
Human Kinetics, Champaign, 1990.

Human Kinetics, Champaign, 1990 .
McKeag DB. Pre-season physical examination for the prevention of sports injuries. Sports Med 1985;2:413-31.

7 Meeuwisse WH, Fowler PJ. Frequency and predictability of sports injury in intercollegiate athletes. Can $\mathcal{F}$ Sport Sci 1988;13:35-42.

8 Taimela S, Kujala UM, Osterman K. Intrinsic risk factors and athletic injuries. Sports Med 1990;9:205-15.

9 Fields KB, Delaney M. Focusing the pre-participation Fields KB, Delaney $M$. Focusing the pre-particin
sports examination. $\mathcal{F}$ Fam Pract 1990;30:304-12.

10 Janda V. Muscle testing and function. Sydney: Butterworths, 1983:230-4.

11 Schache A, Blanch P, Murphy A. The relationship of anterior pelvic tilt during running with clinical and kinematic measures of hip extension. Abstract, Australian Conference of Science of Science and Medicine in Sport, 1997.

\begin{tabular}{|c|c|c|}
\hline \multicolumn{3}{|c|}{ BASM Merchandise 1998} \\
\hline Ties & $\begin{array}{l}\text { Single motif } \\
\text { Multi motif }\end{array}$ & $\begin{array}{l}£ 6+£ 1.50 \mathrm{p} \& \mathrm{p} \\
£ 6+£ 1.50 \mathrm{p} \& \mathrm{p}\end{array}$ \\
\hline Blazer badge & $\begin{array}{l}\text { Wire }-4 \text { inches high } \\
\text { Wire }-3 \text { inches high }\end{array}$ & $\begin{array}{l}£ 5+£ 1.50 \mathrm{p} \& \mathrm{p} \\
£ 5+£ 1.50 \mathrm{p} \& \mathrm{p}\end{array}$ \\
\hline \multicolumn{3}{|c|}{ New stock to order } \\
\hline Sweaters & $\begin{array}{l}\text { Lambswool fine knit, V-neck or round } \\
\text { neck with small motif. Machine washable. } \\
\text { State colour and chest size required. }\end{array}$ & $£ 32+£ 3$ p\&p \\
\hline Sweatshirts & $\begin{array}{l}\text { With small motif. } \\
\text { State colour and chest size required. }\end{array}$ & $£^{2} 25+£^{3} \mathrm{p} \& \mathrm{p}$ \\
\hline Polo shirts & \multicolumn{2}{|l|}{$\begin{array}{l}\text { State colour and chest size required. } \\
\text { Some education polo shirts in cream } \\
\text { and grey are also available at the same price. }\end{array}$} \\
\hline \multicolumn{3}{|c|}{$\begin{array}{l}\text { Send orders to John H Clegg JP BSc LDS RCS Eng, Hon Secretary, } \\
\text { Birch Lea, } 67 \text { Springfield Lane, Eccleston, St Helens, Merseyside WA10 5HB, } \\
\text { UK. (Tel: } 01744 \text { 28198) }\end{array}$} \\
\hline
\end{tabular}

